\title{
ELECTROLYTE CHANGES IN HUMAN STRIATED MUSCLE IN ACIDOSIS AND ALKALOSIS
}

\author{
By GILBERT H. MUDGE 1 AND KATHERINE VISLOCKY \\ (From the Department of Medicine, College of Physicians and Surgeons, Columbia University, \\ and The Presbyterian Hospital in the City of New York)
}

(Received for publication October 14, 1948)

\section{INTRODUCTION}

In recent years many studies have been reported on the monovalent cation composition of the intracellular space during experimentally produced potassium depletion. The most consistent changes have been found in striated muscle and, in general, have shown that decreased concentrations of intracellular potassium are associated with an increase in intracellular sodium. Such changes have been reported in the rat (1), the cat (2), and the dog (2) following low potassium diets. The administration of desoxycorticosterone acetate in large doses has produced similar changes in the same animals (2-4). Recently Darrow has reported comparable findings in association with alkalosis, as determined by muscle analyses in rats (5) and indirectly by balance studies in man (6).

Inasmuch as direct studies of human tissues during states of potassium depletion have not been reported, the present studies were undertaken in an attempt to define the composition of the intracellular electrolytes of striated muscle obtained by biopsy from patients with metabolic alkalosis and acidosis.

\section{METHODS}

Biopsies. Muscle biopsies were taken from the hamstring or gastrocnemius muscles, the average weight of fresh tissue being $2.4 \mathrm{gms}$. Anesthesia was obtained by infiltration of the skin and subcutaneous tissues with 2 per cent procaine in saline. Careful precautions were taken to avoid infiltration of the muscle tissue with the anesthetic agent and it is believed that there was no contamination of the specimens with the possible exception of two cases (Table I, patients G. and To.). In these patients inadequate anesthesia necessitated infiltration of the muscle approximately $10 \mathrm{~cm}$. proximal to the site from which the actual biopsy was taken. A careful analysis of the results obtained from these two specimens reveals no abnormality specifically attributable to the possible inclusion of the anesthetic solution in the specimen, and it is

\footnotetext{
1 National Research Council Fellow.
}

therefore believed that no contamination occurred. Excess blood was removed by blotting the specimen with dry gauze. The tissue was immediately placed in an airtight glass container and analytical procedures were begun within one hour. Venous blood specimens without stasis were taken under oil at the time of biopsy.

"Normal" control muscle specimens and accompanying blood samples were obtained from patients undergoing operations under general anesthesia (Table I), the biopsies being taken from the rectus abdominalis at the start of the operation. The patients had been on a normal diet, had not received previous parenteral alimentation, and were considered to be in a normal state of fluid and electrolyte balance. The alleged normalcy of the control muscles may be subject to question because of possible changes resulting from the anesthetic agents or the underlying disease process. Minor changes may also have resulted from sustaining infusions of glucose and saline started at the time of operation. However, the "normal" values obtained are in essential agreement with previously reported analyses of human skeletal muscle (7), and because of the marked differences between the "normal" and abnormal groups, it is felt that these tissues represent an adequate control for the present study.

Analytical Methods. Determinations were made of the concentration of water, fat, chloride, sodium, potassium, and nitrogen in the tissues. All analyses were done in duplicate. The analytical procedure was that of Lowry and Hastings (8) as modified by Hull (9), with additional modifications for determination of sodium and potassium by an internal standard flame photometer (10). The frèsh tissue was freed of all visible fat and connective tissue and then finely minced with scissors and placed in a $10 \mathrm{cc}$. volumetric tube. The water content was measured by drying in an electric oven at $105-110^{\circ} \mathrm{C}$. to constant weight. Neutral fat was determined by the extraction with ethyl ether of the residue remaining after the evaporation of water, according to the procedure of Hastings and Eichelberger (11). The extracted fat and solvents were returned to the tube and the solvents evaporated. The tissue was digested in a bath of boiling water with $3 \mathrm{ml}$. concentrated nitric acid in the presence of silver nitrate 50 per cent in excess of anticipated chloride. Chloride content was determined by Volhard titration of an aliquot of the digest made up to volume with water. Sodium and potassium were determined on 1 or $2 \mathrm{cc}$. aliquots diluted to the proper volume with the addition of lithium sulfate as an internal standard. Flame photometry yielded an accuracy of 1 per cent, and large 
excesses of nitric acid and inorganic phosphate added to standard solutions introduced no measurable error. $\mathrm{Ni}$ trogen estimations were done on samples of tissue separate from those taken for electrolyte analysis, and nitrogen was determined by micro-Kjeldahl technique. All analyses were corrected for fat-free weight, including nitrogen estimations for which it was assumed that the fat content was the same as in the aliquot used for electrolyte determinations. Duplicate analyses of separate aliquots of minced muscle from 42 specimens analyzed by this method have shown the following average percentile deviation from the mean values: water $\pm 0.2 \%$; chloride $\pm 1.9 \%$; sodium $\pm 1.5 \%$; potassium $\pm 1.2 \%$; and nitrogen $\pm 0.9 \%$.

Serum electrolytes were determined by methods previously reported (3), except that sodium and potassium were determined by flame photometry. Serum $\mathrm{pH}$ was determined by glass electrode.

Calculations. Serum concentrations were corrected for serum water which was either determined directly by drying to constant weight at $110^{\circ} \mathrm{C}$., or estimated from serum protein concentration (8). Extracellular concentrations of sodium, potassium and chloride were calculated using an average Donnan factor of 0.95. Extracellular water (ECW) was calculated as the "chloride space." Intracellular electrolytes were obtained as the difference between tissue and extracellular values and have been expressed in concentrations per liter of intracellular water (ICW). Because tissue hemoglobin, collagen and elastin were not measured, all tissue nitrogen was considered as intracellular, thus introducing a small systematic error of less than 1 per cent (8). For comparative purposes nitrogen has been expressed as grams per liter ICW.

\section{RESULTS}

Nine patients were studied-three controls, three with gastric alkalosis, and three with chronic renal acidosis without glomerular insufficiency (12). The results are given in Table I. The last two analyses of patient $R$. have been excluded from the present discussion because blood specimens were not taken simultaneously with the muscle. Calculated intracellular sodium averaged $8 \mathrm{mEq} / \mathrm{L} \mathrm{ICW}$ in the control group. There is no apparent explanation for the variation of the values within the control group. Both the patients with acidosis and alkalosis showed an increase of intracellular sodium, average values being $32 \mathrm{mEq} /$ $\mathrm{L} \mathrm{ICW}$ for the acidosis group and $20 \mathrm{mEq} / \mathrm{L} \mathrm{ICW}$ in alkalosis. Serum potassium varied from 3.9 to $4.8 \mathrm{mEq} / \mathrm{L}$ for the controls, from 2.5 to $3.7 \mathrm{mEq} /$ $\mathrm{L}$ for the acidotic group, and from 1.8 to $2.7 \mathrm{mEq} /$ $\mathrm{L}$ for the alkalotic group. The increase in intracellular sodium was proportional to the decrease

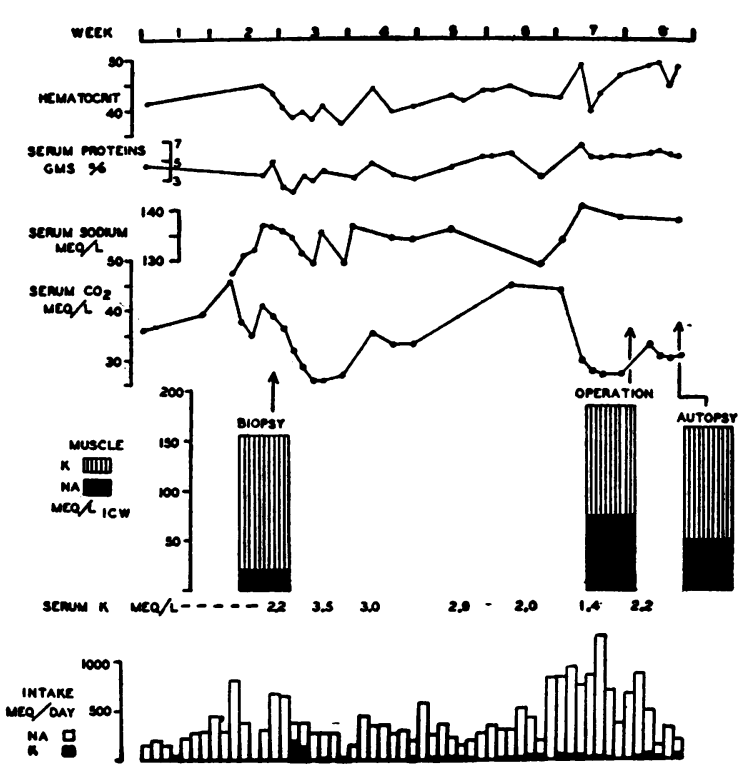

Fig. 1. Clinical Course, Serum Electrolytes, and Intracellular Electrolytes in Patient R. Showing Development of Intracellular Potassium Depletion with Sodium Replacement as Prolonged Alkalosis Was Treated with Parenteral Sodium Chloride Solutions

in intracellular potassium as is indicated by the constancy of the sum of the concentrations of these two cations, average values being $165 \mathrm{mEq} / \mathrm{L}$ ICW for the controls, $163 \mathrm{mEq} / \mathrm{L} \mathrm{ICW}$ for the acidotic subjects and $163 \mathrm{mEq} / \mathrm{L} \mathrm{ICW}$ for the patients with alkalosis. The widest variations of these values was found in the group with alkalosis. The ratio of nitrogen to cell water indicates a relative cellular dehydration in acidosis with a slight increase in hydration in alkalosis. However, the changes in cellular hydration are small and are not definitely conclusive.

The most striking abnormalities were found in the serial analyses of patient R. (Table I and Figure 1) who had persistent vomiting due to a carcinoma of the duodenum. During 63 days he received $239 \mathrm{~L}$ of parenteral fluids, therapy being primarily directed towards the maintenance of a normal hematocrit and normal concentrations of serum sodium, chloride and protein. Random analyses revealed a continuous loss of potassium in vomitus and urine. No parenteral potassium was administered. Although the calculation of the intracellular space in the last two muscle analyses can only be accepted as an approximation because 
TABLE I-A

\begin{tabular}{|c|c|c|c|c|c|c|c|c|c|c|c|c|c|c|c|}
\hline 2arders & $\Delta \cos$ & $\operatorname{sex}$ & Ducuosis & SFEcinke & AnEst:Bst & \multicolumn{10}{|c|}{ SEFun COMCritratiours } \\
\hline & & & & & & $\mathrm{E}_{2} \mathrm{O}$ & Proteln & $\mathrm{HCO}_{3}$ & Cl & In. & $\mathbf{x}$ & Ca & $P$ & Drea $\mathbf{1}$ & $\mathrm{pH}$ \\
\hline & & & & & & $\%$ & $\%$ & $=3 \sqrt{L}$ & $\operatorname{seg} / 2$ & $-39 / 2$ & $n a / 2$ & nex $x$ & and & $\operatorname{mos}$ & \\
\hline 2 & 48 & $x$ & & & $\underset{\text { Cuntothe }}{\text { Pont }}, n_{2} O_{1}$ & 91.2 & & 27.7 & 96.8 & 233 & 4.0 & & & 9 & - \\
\hline $\mathbf{m}$ & 62 & $\boldsymbol{I}$ & Iox=1 & Bootes Abd & $\begin{array}{l}\text { Pentothal, } \mathrm{M}_{2} \mathrm{O} \text {, } \\
\text { Curvere }\end{array}$ & 91.5 & 6.8 & 22.4 & 99.2 & 137 & 3.9 & - & - & 12 & - \\
\hline $\mathbf{x}$ & 82 & $x$ & Iornal I & Iat. Dorel & Pontothal, $\mathrm{I}_{2} \mathrm{O}$ & 90.6 & 7.4 & 24.2 & 94.6 & 234 & 4.8 & - & - & - & - \\
\hline $\mathbf{D}$ & 46 & $x$ & Dopal & Castroo. & Proon1no, 200al & $91.0 *$ & 7.5 & 23.5 & 116.8 & 137 & 3.7 & 9.3 & 2.2 & 16 & 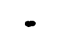 \\
\hline $\boldsymbol{P}$ & 28 & $\boldsymbol{T}$ & Dopol & Gastroo. & Proodine, local & 90.2 & 7.9 & 22.8 & 114.2 & 235 & 2.9 & 8.8 & 2.8 & 28 & $7.25 \mathrm{~V}$ \\
\hline - & 28 & $\boldsymbol{F}$ & $\begin{array}{l}\text { Domel } \\
\text { Lo1dose1: }\end{array}$ & Gestroo. & Proos 1ne, 100id & 90.2 & 7.8 & 11.6 & 213.0 & 138 & 2.5 & 9.5 & 2.2 & 20 & $7.28 \Lambda$ \\
\hline $\mathbf{I}$ & 59 & 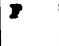 & 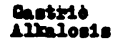 & Ianoting & $\begin{array}{l}\text { Procalne, nexre } \\
\text { bloak }\end{array}$ & 92.7 & 6.5 & 49.0 & 68.8 & 228 & 1.8 & 9.9 & 3.5 & 48 & $7.62 \mathrm{~V}$ \\
\hline 20 & 63 & $x$ & 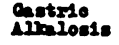 & ancotroe. & Procalm, 100al & 92.4 & 6.2 & 48.8 & 82.8 & 237 & 2.7 & - & - & 17 & $7.52 \mathrm{~V}$ \\
\hline D-1 & 86 & 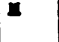 & Antrice & Catroo. & Procen1ne, 100al" & $92.7 *$ & 5.8 & 39.2 & 87.6 & 137 & 2.2 & 9.3 & 2.7 & 26 & $7.68 \mathrm{~V}$ \\
\hline $2-2$ & & & & $\begin{array}{l}\text { Botad } \\
\text { Abe. }\end{array}$ & $\begin{array}{l}\text { Pontothal, } \mathrm{I}_{2} \mathrm{O} \text {, } \\
\text { Curnest }\end{array}$ & 92.94 & 8.6 & 88.9 & 98.0 & 139 & 2.4 & - & - & - & - \\
\hline Is & & & & Iwoene & Antopu & 93.2* & 5.4 & 82.0 & 84.3 & 139 & 2.3 & - & - & 94 & $=$ \\
\hline
\end{tabular}

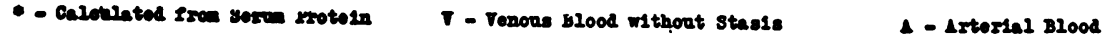

TABLE I-B

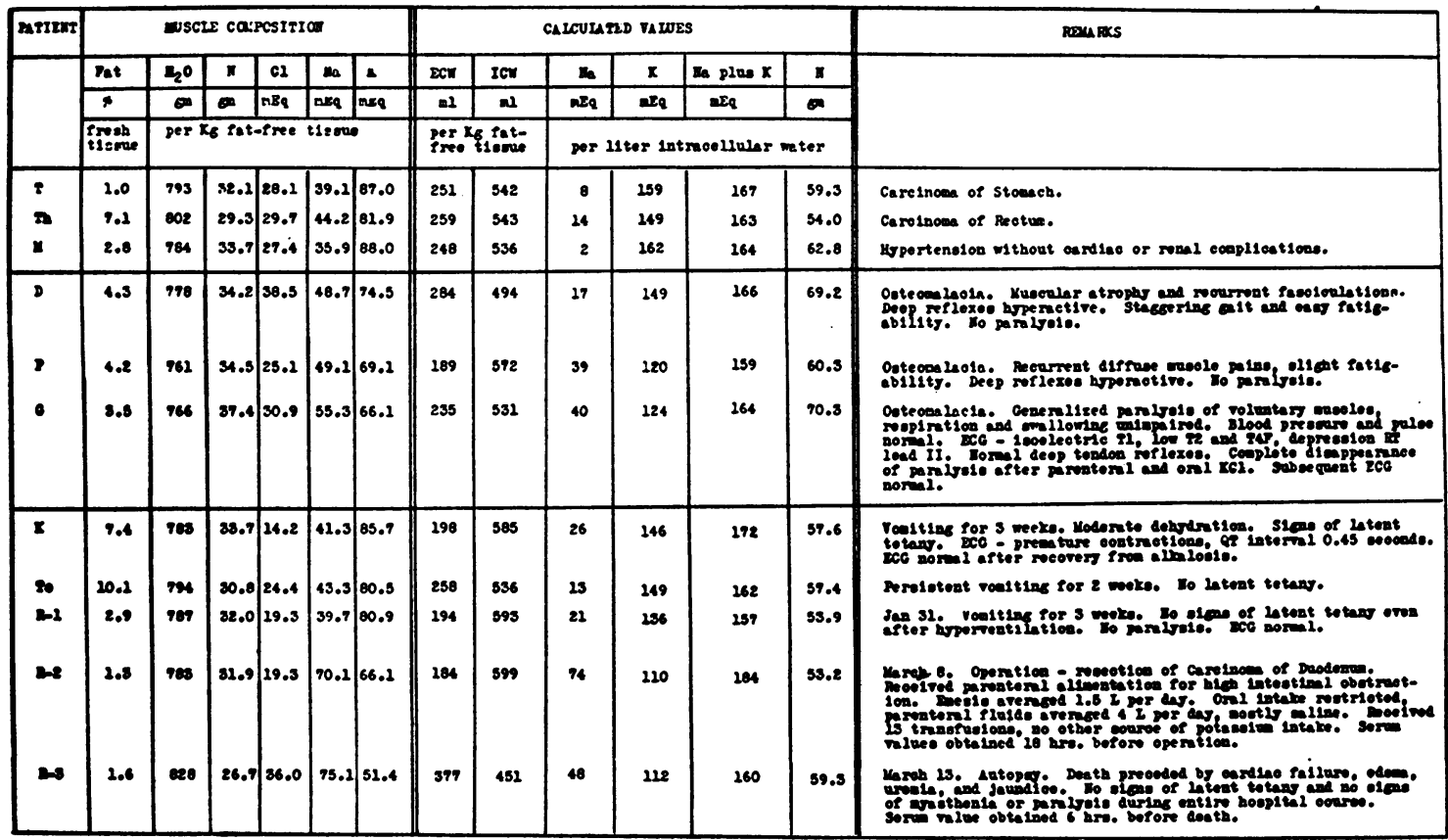

the blood and muscle specimens were not simultaneous, the muscle specimens obtained at operation and autopsy showed, respectively, that 40 per cent and 31 per cent of the intracellular cation was sodium. The serum values for the autopsy specimen were obtained six hours before death, the autopsy being performed 11 hours post mortem. The extent to which post mortem changes may have modified the calculated intracellular values cannot be accurately evaluated at present. 


\section{DISCUSSION}

The calculation of the extracellular and intracellular spaces and the electrolytes contained therein has been based on the concept either that all chloride is extracellular $(11,13,14)$, or that a small but invariable amount of chloride is intracellular (15). Because of inadequate data on human muscle, the possibility of a small constant quantity of chloride within cells has been neglected. However, the obligatory extracellular position of chloride has been challenged by recent experiments in which large doses of potassium chloride were administered $(16,17)$. An analysis of the results reported here indicates that the chloride content of whole muscle varies directly with the serum chloride concentration. Small deviations from an exactly linear relationship may so easily be explained by slight variations in the extracellular fluid volume that we are led to believe that there is no significant alteration in muscle cell permeability to the chloride ion during disturbances of the type reported here. We therefore feel that the use of the chloride space as a measure of the extracellular space is valid for these studies.

Although the number of specimens is too small to warrant definitive statistical analysis, it is apparent in the conditions studied that there has been a loss of intracellular potassium from striated muscle with an increase in intracellular sodium. The human, therefore, responds in a manner qualitatively similar to other species studied.

In recent studies Darrow et al. (18) have demonstrated a correlation between alkalosis and a rise in intracellular sodium in the presence of normal renal function. In acidosis produced by the administration of ammonium chloride to rats, they found a decrease in the amount of sodium within striated muscle cells. Although our studies of acidosis have been limited to a single disease, namely, chronic renal acidosis without apparent glomerular insufficiency, the fact that these patients demonstrate a significant depletion of intracellular potassium and a rise in intracellular sodium in the presence of systemic acidosis indicates that these changes are not necessarily associated with alkalosis of the body fluids. Albright et al. (12) showed that this type of renal abnormality was associated with a negative potassium balance, which has been confirmed by unreported balance studies of two of our patients. These findings, therefore, suggest that the described abnormalities in the intracellular electrolyte pattern may not be specifically related to changes in acid-base equilibria, but rather are a reflection of an overall negative potassium balance, regardless of the immediate cause.

The relationship of disturbances in potassium metabolism to paralysis has been recently reviewed (19). Of our six cases with documented potassium depletion, only one patient developed paralysis (subject G., Table I). On the day of biopsy the patient was unable to walk, feed herself, or turn over in bed. The paralysis had developed gradually during the preceding days and had not been precipitated by a large carbohydrate intake. Serum potassium was $2.5 \mathrm{mEq} / \mathrm{L}$, a value of 2.6 having been obtained on the second and sixth day before the episode of paralysis. Following the administration of parenteral and oral potassium chloride the patient rapidly improved with disappearance of all symptoms of paralysis. During the following two weeks of observation, the serum potassium ranged from 2.8 to $3.2 \mathrm{mEq} / \mathrm{L}$. Although a spontaneous remission cannot be absolutely ruled out, the fact that the paralysis disappeared following the administration of potassium chloride is evidence that the disturbed neuromuscular function was actually caused by a potassium deficit. It is of particular interest, therefore, that the concentrations of potassium in the serum and muscle of this patient were not significantly different from those of the others studied. The findings in patient P. (Table I) were almost identical, yet she had no paralysis. On the other hand, patient $R$. (Table I) showed the greatest potassium depletion, but throughout his hospital course had no manifest disturbances of neuromuscular function. Our limited observations thus fail to reveal any correlation between potassium concentration within skeletal muscle and the appearance of paralysis.

\section{CONCLUSIONS}

1. The association of alkalosis with decreased concentrations of intracellular potassium and increased concentrations of intracellular sodium has been confirmed by analysis of biopsies of human striated muscle. 
2. Similar changes have been observed in patients with systemic acidosis due to chronic renal disease.

3. One patient with severe paralysis attributed to potassium deficit showed intracellular changes which were quantitatively not different from the non-paralyzed patients.

\section{BIBLIOGRAPHY}

1. Heppel, L. A., The electrolytes of muscle and liver in potassium depleted rats. Am. J. Physiol., 1939, $127,385$.

2. Darrow, D. C., and Miller, H. C., The production of cardiac lesions by repeated injections of desoxycorticosterone acetate. J. Clin. Invest., 1942, 21, 601.

3. Ferrebee, J. W., Parker, D., Carnes, W. H., Gerity, M. K., Atchley, D. W., and Loeb, R. F., Certain effects of desoxycorticosterone; development of "diabetes insipidus" and replacement of muscle potassium by sodium in normal dogs. Am. J. Physiol., 1941, 135, 230.

4. Miller, H. C., and Darrow, D. C., Relation of serum and muscle electrolyte, particularly potassium, to voluntary exercise. Am. J. Physiol., 1941, 132, 801.

5. Darrow, D. C., Changes in muscle composition in alkalosis. J. Clin. Invest., 1946, 25, 324.

6. Darrow, D. C., Congenital alkalosis with diarrhea. J. Pediat., 1945, 26, 519.

7. Shohl, A. T., Mineral Metabolism. Reinhold Publishing Corp., New York, 1939.

8. Lowry, O. H., and Hastings, A. B., Histochemical changes associated with aging; methods and calculations. J. Biol. Chem., 1942, 143, 257.
9. Hull, T. Z., Personal communication.

10. Berry, J. W., Chappell, D. G., and Barnes, R. B., Improved method of flame photometry. Ind. \& Engineer. Chem. (Analytical), 1946, 18, 19.

11. Hastings, A. B., and Eichelberger, L., The exchange of salt and water between muscle and blood; the effect of an increase in total body water produced by the intravenous injection of isotonic salt solutions. J. Biol. Chem., 1937, 117, 73.

12. Albright, F., Burnett, C. H., Parson, W., Reifenstein, E. C., Jr., and Roos, A., Osteomalacia and late rickets. The various etiologies met in the United States with emphasis on that resulting from a specific form of renal acidosis, the therapeutic indications for each etiological sub-group and the relationship between osteomalacia and Milkman's Syndrome. Medicine, 1946, 25, 399.

13. Fenn, W. O., Electrolytes in muscle. Physiol. Rev., $1936,16,450$.

14. Dean, R. B., The determination of chloride in single isolated muscle fibers. J. Biol. Chem., 1941, 137, 113.

15. Yannet, H., and Darrow, D. C., The effect of depletion of extracellular electrolytes on the chemical composition of skeletal muscle, liver, and cardiac muscle. J. Biol. Chem., 1940, 134, 721.

16. Boyle, P. J., and Conway, E. J., Potassium accumulation in muscle and associated changes. $\mathrm{J}$. Physiol., 1941, 100, 1.

17. Wilde, W. S., The chloride equilibrium in muscle. Am. J. Physiol., 1945, 143, 666.

18. Darrow, D. C., Schwartz, R., Iannucci, J. F., and Coville, F., The relation of serum bicarbonate concentration to muscle composition. J. Clin. Invest., 1948, 27, 198.

19. Gass, H., Cherkasky, M., and Savitsky, N., Potassium and periodic paralysis. Medicine, 1948, 27, 105. 